\title{
O rejeito e suas diversas marcas: saúde dos trabalhadores da Defesa Civil no rompimento da barragem de Fundão
}

\author{
The reject and its various brands: health of Civil Defense workers in \\ the rupture of the Fundão dam
}

Eduardo de Andrade Rezende ${ }^{\mathbf{1}}$, Sergio Portella ${ }^{\mathbf{1}}$, Simone Santos Oliveira ${ }^{\mathbf{1}}$

DOI: $10.1590 / 0103-11042020$ E219

RESUMO A partir do desastre socioambiental ocorrido em Mariana (MG), em 5 de novembro de 2015, o estudo buscou compreender a atividade dos técnicos da Defesa Civil que atuaram no desastre. A reflexão que aqui se desenvolve parte do esforço de dar visibilidade à atividade desses profissionais que atuam em condições permeadas de imprevisibilidades e pressões. O estudo tem como referenciais os aportes do campo da Saúde do Trabalhador e da ergologia. Trata-se de uma pesquisa empírica, de abordagem qualitativa, realizada por meio de observação direta e entrevistas individuais semiestruturadas com trabalhadores da Defesa Civil. A análise dos resultados foi organizada em duas grandes seções com os seus respectivos desdobramentos: a primeira traz uma contextualização do desastre narrada pelos diversificados profissionais que atuaram; a segunda evidencia desafios e perspectivas que os agentes de defesa civil puderam tirar da catástrofe. Diante da complexidade das situações e da dimensão imprevisível do risco, os agentes de defesa civil são constantemente convocados a 'renormatizar' e a operar escolhas a partir de sua história e de seus valores para lidar com as infidelidades do meio.

PALAVRAS-CHAVE Defesa Civil. Planejamento em desastres. Represas. Saúde do Trabalhador.

\begin{abstract}
From the socio-environmental disaster that took place on November 5 th, 2015 in Mariana (MG), the study sought to understand the activity of Civil Defense technicians who acted in the disaster, aiming to collaborate for actions of worker's health surveillance. The reflection that develops here is part of the effort to give visibility to the activity of those professionals who work in conditions permeated with unpredictability and pressure. The study has as references the contributions from the field of Occupational Health and ergology. This is an empirical research with a qualitative approach, conducted through direct observation and semi-structured individual interviews with Civil Defense professionals. The analysis of the results was organized in two large sections with their respective consequences: the first brings a contextualization of the disaster narrated by the several professionals who worked during it; the second focuses on the challenges and perspectives that civil defense agents have been able to draw from the disaster. Faced with the complexity of situations and the unpredictable dimension of risk, civil defense agents are constantly called upon to 'renormatize' and operate choices based on their history and their values to deal with environmental infidelities.
\end{abstract}

KEYWORDS Civil Defense. Disaster planning. Dams. Occupational healthy.

1 Fundação Oswaldo Cruz (Fiocruz) - Rio de Janeiro (RJ), Brasil.

sssoliver@gmail.com 


\section{Introdução}

O tema desastres cada vez mais ocupa espaço nas agendas acadêmicas, institucionais e políticas. Se, por um lado, o aumento de suas ocorrências é evidente, exigindo maior organização, com formulação de leis, manuais, protocolos, por outro, as inúmeras questões que decorrem desses eventos, que colocam em destaque suas diversas dimensões, ainda merecem olhar mais apurado. Ressaltamos aqui a importância do trabalho da Defesa Civil no novo arcabouço da cultura do risco que as políticas públicas em Redução de Riscos e Desastres (RRD) querem atingir. Esses profissionais ainda não possuem identidade definida institucional e suas atuações nos eventos emergenciais ficam envoltas em um conjunto de ambiguidades institucionais que os colocam em dilemas que são impelidos a resolver na atividade em curso. Essa vivência repercute negativamente em sua saúde agravando ainda mais as consequências dos desastres.

Quando se fala desastre, muitas são a definições e imaginações evocadas, por isso seguimos Quarantelli', um dos pioneiros em pesquisas sociais sobre desastres, que nos faz aprofundar as reflexões e nos direciona para um conceito amplo de desastre quando diz:

Desastre não é um acontecimento físico [...] trata-se de um acontecimento social. Assim, não é apropriado falar em desastres 'naturais' como se pudessem existir fora das ações e decisões dos seres humanos e suas sociedades ${ }^{1(41)}$

Assim, os desastres seriam processos multidimensionais e multicausais sociais, como enfatiza $A \operatorname{costa}^{2}$, e não paisagens raras, remotas e livres de pegadas humanas. Ao contrário, só há desastre porque há um meio social diretamente envolvido no acontecimento físico de devastação. Desastre, em essência, é um problema atinente ao meio social. Uma pergunta central feita por Valencio ${ }^{3}$ é: qual o processo social que o desencadeou? Se acaso a pergunta central for outra, dirigida à natureza em fúria, isso inviabiliza que os grupos afetados tenham recursos de voz.

Nesse contexto, cabe discutir e definir os desastres baseados na abordagem social, cujos estudos têm início na década de 1940 e ganham força e estrutura a partir de 1960. Destacam-se os estudos conduzidos na América Latina, no final da década de 1980, e são concentrados pela Red de Estudios Sociales en Prevención de Desastres en América Latina (LA RED), formada em $1992^{4}$. Dessa forma, o desastre socialmente construído só pode ser entendido como resultante de processos sociais: "Tanto las causas como las consecuencias de los desastres son producto de procesos sociales que existen en el interior de la sociedade"5(80).

Naturalizar os desastres é um ato que condiciona toda a atividade de gestão de RRD. Esse ato de naturalização, para Portella ${ }^{6}$, é tão comum em nossa sociedade, que diante dos desastres de origem tecnológica humana, que aparentemente não poderiam ser escondidos debaixo dessa capa da natureza descontrolada, mesmo assim, tenta-se classificá-lo sob a égide do natural, como no caso do rompimento da barragem da mineradora Samarco.

Em menos de cinco anos, o Brasil assistiu a dois desastres tecnológicos de grandes proporções e consequências graves, mas previsíveis, reconhecidos assim como crimes.

O primeiro ocorrido no dia 5 de novembro de 2015 pelo rompimento da barragem de Fundão (administrada pela Samarco), em Mariana (MG), considerado o maior desastre da mineração brasileira em nível de extensão territorial e danos ambientais, afetou a vida de milhares de pessoas tanto em território mineiro quanto capixaba. A tragédia atingiu os distritos de Bento Rodrigues e Paracatu de Baixo e pode provocar o surgimento de estranhos desertos de lama. O distrito de Bento Rodrigues, localizado a 2,5 km do barramento, foi o mais atingido pelo fluxo dos sedimentos, sendo completamente destruído. O desastre causou de imediato 19 mortes, e liberou cerca de 50 milhões de metros cúbicos de resíduos 
de minério que, carreados até o Rio Doce, percorreram aproximadamente $600 \mathrm{~km}$ até o litoral do Espírito Santo 7,8.

O segundo, ocorrido em 25 de janeiro deste ano, no município de Brumadinho, quando por falta de precaução e prevenção, apesar de indicativos de risco em laudos, a mineradora Vale S.A. foi responsável pelo maior desastre do trabalho em barragens de rejeitos no Brasil. No rompimento da Barragem I da Mina do Córrego do Feijão, entre mortos e desaparecidos, tem-se um número próximo de 300 pessoas 9 .

Desastres dessa grandeza influenciam de forma significativa no quadro de adoecimento da população e dos trabalhadores envolvidos. Além disso, nos últimos anos, o Brasil vem passando por intensa urbanização e industrialização e alterações ambientais profundas resultantes da combinação de ambos, tornando os desastres mais frequentes. Essa realidade tem exigido do campo da Defesa Civil constante revisão de seu arcabouço jurídico, do seu sistema de ação e, sobretudo, consciência das suas fragilidades institucionais em lidar com todos estes problemas ${ }^{10}$.

Nesse sentido, o objetivo principal da pesquisa foi compreender a atividade dos técnicos da Defesa Civil que atuaram no crime da Samarco em Mariana (MG), visando contribuir para ações em Saúde do Trabalhador (ST) nas políticas de RRD. O campo da ST emerge, do ponto de vista acadêmico, político e institucional na saúde coletiva, em contraposição à base conceitual e prática das concepções hegemônicas sobre a relação trabalho-saúde da medicina do trabalho e da saúde ocupacional. Para a ST, o processo de trabalho é uma categoria fundamental, que possibilita análises sobre o adoecimento e o sofrimento ultrapassando uma visão simplista, mono ou multicausal. Na investigação sobre o processo de trabalho e riscos à saúde, é imprescindível a participação dos trabalhadores como sujeitos desse processo por meio da valorização das suas experiências"1. Portanto, a reflexão que aqui se desenvolve parte do esforço de dar visibilidade ao trabalho desses profissionais que atuam em desastres, buscando valorizar essas experiências de enfrentamento na fase de resposta e recuperação. Uma experiência singular que se expressa em um corpo, biológico, social e político, que, por meio da história, transforma-se em patrimônio de quem trabalha' ${ }^{\mathbf{1 2}, 13}$.

\section{Defesa Civil no Brasil e a perspectiva ergológica}

$\mathrm{O}$ atual marco regulatório do Sistema Nacional de Proteção e Defesa Civil (Sinpdec) e da Política Nacional de Proteção e Defesa Civil (PNPDEC) é recente e complexo, compreendendo uma série de leis, decretos e instruções normativas que versam sobre as atribuições do Sinpdec e da PNPDEC. Dentre os quais, destacam-se: a Lei ${ }^{0} 12.608$ e a Instrução Normativa ${ }^{\circ} 01$, de 2012; e a Lei n ${ }^{0} 12.983$, de $2014^{14}$.

Segundo Rocha ${ }^{\mathbf{1 0}}$, pelo histórico da Defesa Civil, trata-se de um campo de atuação do serviço público com finalidade social de prestar socorro e assistência a populações em momentos de crise. No entanto, aponta a autora, a institucionalização e as leis que estabelecem diretrizes de ações emergiram como agendas públicas importantes somente a partir dos desastres nos anos recentes.

Apesar de seus avanços, a Lei ${ }^{\circ} 12.608$ depende ainda de muitos marcos regulatórios que a viabilize na prática, e sua letra fria esconde que ela foi um campo de intensos debates e controvérsias na sua constituição. A Comissão Especial de Medidas Preventivas e Saneadoras de Catástrofes Climáticas da Câmara dos Deputados, constituída por Ato da Presidência de 10 de março de 2011, há apenas dois meses do Desastre das cidades serranas, em seu relatório final, de novembro de 2011, propunha a instituição de uma Política Nacional de Proteção Civil. A inclusão da expressão 'e defesa' no objeto instituído pela lei publicada indica a controvérsia de manter como referência a estrutura anterior 
submetendo a ela a nova estrutura que queria nascer, a de proteção civil, pois:

No Brasil, a lei 12.806 de Prevenção e Defesa Civil reforça essa militarização da ajuda, ao facilitar que as defesas civis - órgãos eminentemente de prevenção - sejam preferencialmente assumidas pelos bombeiros militares do país, como melhor opção de gestão. E não se trata, obviamente, de pôr em causa a competência e dedicação dos bombeiros na resposta aos desastres, mas antes de discutir o modelo e lógica subjacentes a tais opções ${ }^{6(3)}$.

Cria-se uma ambiguidade institucional em que o mais geral, proteção civil, que inclui todo o ciclo de desastres (preparação, resposta, mitigação e restauração), fica submetido ao mais específico, a capacidade de resposta. Essa ambiguidade vai se refletir em todos os níveis da constituição de defesas civis do País. Ademais, os profissionais da Defesa Civil ficam a meio caminho tendo que dar conta dessa ambiguidade, em que vivenciam uma quantidade impressionante de dilemas e têm sua saúde impactada.

Na constatação de que o meio de trabalho é sempre variável e imprevisto, portanto, de alguma forma infiel e que são os trabalhadores que devem dar conta desta infidelidade, Schwartz ${ }^{15}$, a partir da perspectiva ergológica, afirma que é necessária uma mobilização das capacidades e dos recursos, além das escolhas a serem feitas, deixando o trabalho de ser uma mera execução, mas um uso de si.

Essa perspectiva destaca que em toda atividade humana estão presentes debates de normas, valores e a dupla antecipação. A primeira antecipação refere-se à atividade de conceituação; àquela que se dá antes que cada um tenha encontrado o meio no qual realizará sua atividade. A segunda antecipação, a do encontro do protagonista com a atividade a ser realizada, requer, do sujeito, do corpo-si, que realize renormatizações e ressingularizações das normas antecedentes, no aqui e agora da atividade. Esse encontro é sempre singular, imprescritível, pois cada um "antecipa o outro, em seu próprio esforço, para tornar inteligível um meio de vida ou de trabalho"16(2), nele está presente a relação entre o 'sujeito', o conceito e a vida. O debate de normas (regras, prescrições) e de valores, intrínseco à atividade humana, aparece justamente a partir do hiato existente entre o que é da ordem do geral, previsível e normatizado (prescrito) e o que é da ordem do singular, do real da atividade, da experiência do aqui e agora ${ }^{17}$. Perspectiva que ilumina o debate que ora se coloca sobre a Defesa Civil.

\section{Metodologia}

Assim, para compreender a relação entre trabalho e saúde, é necessário basear-se na vivência dos trabalhadores. São eles que realizam o trabalho. É do sujeito na ação que se exige o empenho para fazer o trabalho; é ele quem analisa as condições que tem para realizá-lo; é ele que sofre o desgaste físico, mental e emocional; é ele que, por fim, adoece, sofre acidentes ou, mesmo, morre. Portanto, a abordagem qualitativa aqui aplicada é mais apropriada para compreensão dessa realidade.

Nesta pesquisa empírica, foram produzidos dados em campo, a partir da realização de entrevistas individuais semiestruturadas e observação direta com registros fotográficos e diário de campo ${ }^{\mathbf{1 8}}$.

O trabalho de campo ocorreu em outubro de 2017. Foram visitadas as localidades de Bento Rodrigues e Paracatu de Baixo, onde a equipe foi acompanhada por profissional de Defesa Civil e voluntários que atuaram na resposta ao evento.

Foram realizadas dez entrevistas efetuadas com agentes da Defesa Civil municipal e estadual. Para tal, foi utilizado um roteiro para mediar as entrevistas, cujas questões abordavam a experiência, os procedimentos, normas e protocolos que contribuíram para a atuação, as dificuldades enfrentadas bem como a relação 
saúde e trabalho, entre outras. Procurou-se manter uma postura dialógica, coerente com as orientações da perspectiva ergológica, que considera que a produção de saberes sobre o trabalho não constitui uma tarefa privativa dos acadêmicos - o que, isoladamente, resultaria em uma visão mutilante do trabalho ${ }^{15}$.

Com o objetivo de resguardar as identidades, todos os profissionais da Defesa Civil gestores e técnicos - foram aqui identificados como agentes de proteção e defesa civil, sendo atribuídas letras (DC-A, DC-B, DC-C) para distinguir a fala desses profissionais.

A análise do material de campo e das entrevistas se deu com base no referencial teórico da ergologia e do campo da $\mathrm{ST}^{19}$ buscando articular conceitos e identificar núcleos temáticos.

Esta pesquisa foi submetida e aprovada pelo Comitê de Ética em Pesquisa da Escola Nacional de Saúde Pública Sergio Arouca, com parecer de número 2.478.561.

\section{Rastros de um desastre em curso pelos olhos de quem o viveu}

É preciso reafirmar o óbvio esquecido: os profissionais de emergências e desastres, junto com a população local, também são afetados por esses eventos. Cotidianamente, entram e saem de cenas de sofrimento sem tempo para refletir e processar essas vivências - permeadas de perdas materiais, mutilações, mortes e histórias de vida compartilhadas - que influenciam sua vida pessoal e profissional. Mais preocupante ainda: não são acolhidos, não há escuta nem levantamento de suas necessidades após o término do incidente traumático ${ }^{20}$. Esses acontecimentos deixam marcas significativas na vida dessas pessoas.

Além disso, o despreparo dos profissionais envolvidos e as dúvidas de como agir em um desastre de grande magnitude ficaram claramente evidenciados nas falas dos trabalhadores entrevistados.
A caminho do local do rompimento, tivemos a oportunidade de conversar com uma agente da Defesa Civil. Ela nos contou o 'pesadelo' que vivenciou por consequência do desastre:

Chegava em casa e chorava todos os dias, por dois meses consecutivos. Como um filme, a cena passava repetidamente na minha cabeça. Demorei aproximadamente um ano para retornar a um dos locais afetados. (DC-A).

A tese defendida por Valencio ${ }^{21}$ de que o desastre não termina logo após a ocorrência do impacto se confirma ao estudarmos o caso de Mariana (MG). As consequências estão presentes no cotidiano da população e dos profissionais até hoje, o que demonstra o quanto o desastre se configura em um processo complexo e duradouro e não se esgota no dia do desastre.

Após quase dois anos do crime ocorrido, ao andar pelos subdistritos de Bento Rodrigues e Paracatu de Baixo, ainda era possível observar o que sobrou dos vilarejos. Por todo o lado, havia objetos que contavam histórias de quem um dia viveu ali. Sobre o chão coberto de lama seca, cama, geladeira, colchão, sofá, calçados, restos de móveis e de vestimentas e brinquedos revelavam como a vida nas comunidades foi abruptamente interrompida, mostrando que o desastre implicou também a perda de objetos simbólicos que representam valores, memórias e histórias de vida. Perdas de difícil reparação.

Em Paracatu, apesar dos riscos e das péssimas condições de moradia, encontramos algumas pessoas que, devido ao forte sentimento de pertencimento ao lugar, insistiam em continuar vivendo ali.

Durante nossa visita a Bento Rodrigues, encontramos um ex-morador, aposentado da Samarco, que desde os 6 anos residia no vilarejo. Em uma conversa informal, contou-nos como foi o dia do rompimento e o quanto isso impactou sua vida. O fato de possuir dupla moradia, uma casa em Mariana e outra em Bento que fora destruída pelo rompimento da barragem, fez com que a empresa não o 
enquadrasse no grupo de moradores atingidos, não o indenizando de igual maneira aos que possuíam apenas residência em Bento.

Tivemos ainda a oportunidade de conhecer a sede da comissão dos atingidos de Bento e Paracatu, onde vimos os mapas com as propostas de reconstrução dos novos povoados. O reassentamento participativo é fruto de longas negociações entre a Comissão de Atingidos, o Ministério Público e a Fundação Renova (criada em agosto de 2016 pela Samarco e governo e que conduz todas as ações de reparação e indenização). É possível ler nos mapas frases escritas pelos atingidos: 'Não venham tirar nosso direito de propriedade'; 'Temos coração e alma'; 'Barragem em Paracatu nunca'; 'Mariana vive, Paracatu respira'.

A definição de atingido, das muitas controvérsias sociotécnicas envolvendo as questões de reparação, foi uma das mais sensíveis. Uma luta entre atingidos que queriam reconhecimento e a Fundação Renova que detinha a legitimidade de defini-los. Como o desastre, essa luta ainda não terminou.

\section{Dilemas e renormatizações}

Por meio das entrevistas realizadas com agentes da Defesa Civil de Mariana e Belo Horizonte, buscou-se refletir sobre os desafios, as limitações e as perspectivas presentes no sistema de Defesa Civil. Para isso, analisaram-se os relatos dos entrevistados agrupando-os em quatro categorias temáticas: intersetorialidade, interdisciplinaridade, intersubjetividade e relação saúde e trabalho. Tais categorias foram escolhidas por comporem o campo de saberes e práticas da ST.

Mediante essas entrevistas, foi possível apreender as experiências e vivências dos profissionais da Defesa Civil que atuaram nesse desastre: as dramáticas do uso de si, as renormatizações, as relações interdisciplinares e intersetoriais, bem como a compreensão que esses trabalhadores têm da saúde.
É uma coisa que a gente sempre fala: gerir segurança significa tomar decisão. Pra tomar decisão tem que ter coragem. Porque muitas vezes você toma decisões que violam, agridem alguns direitos. Às vezes você tem que chegar e tirar. Pra decidir com segurança só com conhecimento. O mundo é dinâmico. (DC-C).

Constantemente, os técnicos da Defesa Civil são convocados a tomar decisões, a renormatizar as normas antecedentes de sua atividade. O profissional é intimado a fazer uso de si e a convocar de sua vida singular o conhecimento que detém, para fazer escolhas e agir pelo coletivo. Desse modo, podemos dizer que, ao longo da vida profissional, o sujeito implica-se, no uso de si, definindo seus critérios éticos para atender às convocações que, dramaticamente, advêm da imprevisibilidade do meio.

A fala reforça aquilo que já é sabido: a imprevisibilidade é um elemento radicalmente perceptível e presente nas atividades de técnicos da Defesa Civil. Ainda que, em cada situação, seja necessário análise prévia para a definição de um plano de atuação, o meio sempre oferece novos fatores. No entanto, justamente por causa das variabilidades e imprevisibilidades, a prescrição é fundamental.

[...] Não existe uma receita de bolo. Então, é importante que as pessoas tenham capacidade de refletir, tomar decisões no momento correto e de acordo com a técnica. Porque você chega no local, o cenário é diferente, as condições são diferentes. E o que faz a diferença de um profissional que tem sucesso e de um profissional que fracassa é a capacitação e a capacidade dele de tomar decisões. (DC-C).

Os gestos, o olhar, a mão como suporte, o corpo-si e até o silêncio passam por escolhas conscientes, habitadas em um drama interior. Essas escolhas são baseadas nas competências e nos valores acumulados ao longo dos tempos e da vida do trabalhador ${ }^{15}$.

Especialmente nos municípios, os órgãos de proteção e defesa civil brasileiros apresentam, na maior parte dos casos, equipes 
muito reduzidas, muitas delas engrossadas nos momentos de emergência. Problemas como o sucateamento da Defesa Civil foram um ponto levantado:

A Defesa Civil no Brasil está sucateada por uma má gestão dos nossos governantes, em detrimento de uma gestão de riscos de desastre. Então a gente tá realmente complicado em relação a isso. (DC-B).

A mídia foi outro dificultador apontado na execução das ações:

A todo momento (a mídia) divulgava informações infundadas sobre os atingidos, dificultando assim o nosso trabalho. Num primeiro momento, por exemplo a mídia disse que havia mais de 300 mortos. E a gente, preocupado porque teria que dar conta. (DC-B).

Segundo Oliveira ${ }^{22}$, para a atuação nos desastres, também devemos considerar como fundamental a intersetorialidade, que, na maioria das vezes, não se realiza sem conflitos e disputas de poder. Em relação à articulação entre a Defesa Civil e os órgãos do município, o agente de proteção e defesa civil A diz ter havido um bom relacionamento entre ambos.

Os órgãos municipais, secretaria de saúde, secretaria de obras, secretaria de meio ambiente, secretaria de transporte, estradas e sinais, secretaria de assistência social, de governo, enfim, as secretarias, os setores envolvidos ali, o nosso relacionamento foi muito bom. O pessoal respeitou bem a hierarquia, o posto de comando, aquele negócio todo. (DC-A).

A importância da articulação entre a Defesa Civil e os demais setores e instituições é de extrema importância para o êxito e a agilidade nas ações. A intersetorialidade, segundo Junqueira $^{23}$, é a articulação de saberes e experiências no planejamento, realização e avaliação de ações, em busca de resultados integrados para situações complexas. Tal fato pode ser observado na fala do agente de proteção e defesa civil do município mineiro de Belo Horizonte:
[...] hoje, na rotina de Belo Horizonte, nós temos aqui o centro de operações e nós conseguimos dentro desse centro de operações de $B H$, implantar uma visão de que a cooperação, a participação cooperativa dos órgãos é o que viabiliza o sucesso e a rapidez no atendimento às necessidades do cidadão. (DC-C).

A equipe da Defesa Civil de Mariana é composta por um número pequeno de membros. Mesmo diante de um número reduzido de técnicos, a equipe é formada por profissionais de diferentes áreas. Embora eles sejam concursados para o cargo de guarda civil e designados para a função de agente de Defesa Civil, a maioria buscou por conta própria aprimorar conhecimentos que somassem às ações do novo setor:

Nós somos 7 agentes. A maioria é graduado. Nós temos aqui assistente social, pedagoga, bióloga, mas a maioria aqui é formado em tecnólogo de trânsito. Aliás, praticamente toda a guarda é formada de tecnólogo em Segurança Pública, com pós-graduação em trânsito. Enfim, a minha equipe é multidisciplinar. (DC A).

Na ausência de um profissional com habilidades e conhecimentos específicos para a realização de determinada ação, a prefeitura 'cede' do seu quadro de funcionários esse trabalhador à Defesa Civil.

Assim como em Mariana, a interdisciplinaridade é um traço marcante na estrutura da Defesa Civil de Belo Horizonte:

[...] os nossos vistoriadores eles são capacitados para fazer avaliações de risco. Quando se percebe um risco potencial maior, aí sim nós acionamos a nossa diretoria técnica de gestão de riscos, que é um corpo de engenheiros. E quando se percebe que a amplitude do desastre pode ser maior, aí nós pedimos ajuda aos universitários. Nós temos convênios com as universidades. (DC C).

Tais observações, todavia, não são comuns a todas as Defesas Civis. Conforme Siena e 
colaboradores $^{23}$, a falta de uma equipe multiprofissional na composição da Defesa Civil é uma constante.

Com relação à saúde desses profissionais e suas estratégias para agir, segundo Alves20(56),

[...] muitos profissionais podem se sentir identificados com as vítimas, principalmente ao lidar com a exposição de corpos de crianças e com as histórias de vida gerando forte impacto emocional.

Dessa forma, as tragédias acabam por misturar status e papéis sociais. Nesse exemplo, o agente da Defesa Civil também se espelha no desempenho dos papéis da mãe e do pai que se encontram em territorialidade suscetível com seus filhos ${ }^{24}$.

[...] comento sempre a situação [...] da mãe procurando informações. Meu filho tinha mais ou menos a mesma idade, então você tem que se manter firme. E chegou um momento que ela falou 'Ah, eu já sei que meu filho tá morto. Eu só quero enterrá-lo'. Joga aquilo pra cima da gente, sabe? Você se sente inútil, incapaz. Até hoje fica na minha memória. O rosto e o sofrimento da mãe de uma criança de 7 anos. Não tem nem argumentos para descrever aquele sentimento naquele momento. (DC-B).

Com a ocorrência de uma situação trágica, os profissionais envolvidos tornam-se suscetíveis às mesmas consequências emocionais dos atingidos. É possível perceber neles o sentimento que oscila entre a onipotência e a impotência que pode acarretar transtornos emocionais, fazendo-se necessária a busca por suportes técnicos e teóricos para garantir o apoio também a esses trabalhadores ${ }^{25}$.

[...] acaba que a gente toma as dores das pessoas. Começa a chover você lembra da Dona Maria que mora lá no alto do morro, que tem cinco crianças e que tem um barranco enorme em cima da casa dela. Que se a chuva continuar, pode soterrar a casa dela. Aí você lembra do outro que mora na beira do rio. (DC-A).
Existem ainda casos em que os agentes de Defesa Civil vivenciam situações de grande tensão ao mesmo tempo que precisam ser a base de apoio para a população assistida.

Teve uma senhora aqui uma vez, que pediu pra que nós fôssemos fazer avaliação lá de uma escada para ela. Ela morava no segundo andar. O vistoriador foi lá. Ele chegou lá e ficou derrotado. Por quê? A senhora era cadeirante, a família a colocou lá no terraço, onde ela não tinha acesso, deixou ela sozinha, jogada lá. E quando ele chegou que ele foi ver as trincas, 'essa trinca aqui é muito simples, porque ela é muito pequena'. E a senhora 'não, eu só queria que você me desse um abraço, conversasse comigo'! Aí é difícil. (DC-C).

O apoio da gestão e o atendimento dos profissionais da saúde aos trabalhadores que atuam em desastre são de extrema importância para ajudá-los a lidar com os efeitos da tragédia e para evitar adoecimentos futuros. Questionados se tiveram assistência médica ou atenção psicossocial durante ou após o desastre, a grande maioria dos entrevistados respondeu que não.

Não, a gente não teve esse acompanhamento. Não fomos procurados. Se eu falar pra você que eu fui procurado, eu não fui. Nem pela Fundação, nem pela Samarco, nem pelo próprio município. (DC-A).

Ninguém pensa no trabalhador, sabe? Nós temos hoje um número muito grande de pessoas que fazem uso de medicamento controlado pra suportar. É uma realidade, sabe? É estudante, é funcionário... então assim, eu acho que se tivessem mais trabalhos, mais visão, sabe? Do próprio governo em cuidar do trabalhador, não tinha tanta necessidade. Mas não tem, aqui não tem. (DC-F).

Além da falta de acolhimento, há uma exigência técnica, física e emocional grande sobre esses trabalhadores que prejudica a própria atuação.

Eu fiquei em choque... não consegui ir até o local. O coordenador disse: 'Vamos lá, vamos ajudar'. Eu 
disse: 'Olha, eu não consigo'. Então por aí a gente vê como é a limitação. Eu não consegui e disse: 'olha, manda outra pessoa, porque eu não consigo'. Sabe, fiquei com tanto medo, um medo tão grande, sabe, de chegar? Fiquei estagnada. (DC-F).

Nas entrevistas, observamos demandas por atendimento em saúde mental. Estresse pós-traumático, problemas no sono, erupções cutâneas desencadeadas por situação de grande estresse foram alguns dos quadros clínicos relatados pelos entrevistados.

[...] eu fui ver o impacto disso na minha saúde depois. Ali 'tava' sobre adrenalina né, mas depois eu fui sentir o impacto. Cansaço físico, mental e até desenvolvi psoríase. Depois dessa tragédia eu acabei desenvolvendo essa psoríase. Então assim, eu fui sentindo esse impacto depois que as coisas foram normalizando e te confesso o seguinte, já vai fazer anos que aconteceu essa tragédia e até hoje tenho que lidar e gerenciar esse desastre. (DC-A).

Corroborando as teses da perspectiva ergológica de que os trabalhadores possuem um saber investido que a experiência lhes dá e que, muitas vezes, são mais importantes do as próprias prescrições vigentes, um dos agentes de Proteção e Defesa Civil discorre cuidadosamente sobre a importância da preocupação com a ST de Defesa Civil ser incorporada aos treinamentos desses trabalhadores para que possa se chegar a uma verdadeira cultura do risco.

Ela tem que fazer parte da capacitação, dos cursos de Proteção e Defesa Civil de Gestão de Risco de Desastres. Ela tem que ser uma matéria onde os trabalhadores conheçam os limites, as consequências e os problemas que podem afetar sua saúde, e eles mesmos serem capazes de abrir mão de posições dentro do Sistema de Comando e Operações a partir do momento que esses sintomas aflorarem. Então tem que fazer parte na verdade da cultura de Gestão de Risco de Desastre. Tem que deixar de ser herói para ser humano, porque quando você não faz isso o seu aspecto psicológico começa a influenciar no tratamento com os afetados. Então a sua paciência começa a diminuir, você já não tem mais a amabilidade do início pra tratar as pessoas, você fica irritado, o esgotamento físico começa a se manifestar em diversas manifestações de raiva, de impaciência. (DC-D).

Esse agente ainda conclui que essa capacitação do trabalhador deveria fazer parte de todo o Sistema Nacional de Proteção e Defesa Civil. E vai além, sugerindo que essa matéria deveria estar em todas as faculdades, porque defende - toda a sociedade faz parte da gestão do risco a partir da atividade de cada um. Para esse profissional, a relevância e a importância do tema de RRD e da proteção da saúde dos trabalhadores aí envolvidos diretamente são uma certeza diante da sua experiência de escalada cotidiana dos desastres em nossa sociedade. Mesmo que como profissional viva a ambiguidade institucional de ser Defesa Civil, sabe que é preciso avançar para um sistema mais racional e humano, e que essas duas características não estejam apartadas.

\section{Considerações finais}

Em pouco mais de três anos, o Brasil sofreu dois grandes desastres envolvendo barragens de mineração: o de Mariana em 2015 e o de Brumadinho em 2019. Eles trazem à tona a necessidade do aprofundamento no debate sobre a exploração minerária no Brasil, especificamente, e dos desastres, em geral. Ademais, evidenciam a insustentabilidade do atual modelo de exploração minerária implementado no Brasil. Além dos impactos ambientais resultantes, minorias frágeis politicamente e vulneráveis do ponto de vista socioeconômico sofrem de maneira desigual com as ações da mineração.

Como não bastasse, o atual governo federal, por meio do Decreto ${ }^{\circ} 9759$, de 11 de abril de 2019, extinguiu e desmobilizou vários conselhos públicos regulares e elaboradores de política pública, entre eles, o Conselho Nacional de Proteção e Defesa Civil. 
Em relação à Defesa Civil, aponta-se que, embora houvesse articulação entre os setores, ela ainda é um órgão sucateado com um número pequeno de profissionais remanejados para o setor. O despreparo técnico, a falta de treinamentos e protocolos assim como a pressão da mídia foram fatores que dificultaram a ação no desastre.

Da relação trabalho-saúde, ressalta-se que os agentes de Defesa Civil necessitam de acompanhamento psicossocial para lidar com o sofrimento e com a pressão dos trabalhos. São pessoas igualmente vitimadas pelos danos à saúde e pelas tragédias que atingem a população.

Compreende-se, portanto, que é necessária uma transformação nos modos de trabalhar, associada a uma mudança nas práticas de atenção à saúde dirigidas aos trabalhadores, para que se potencialize a saúde. São imprescindíveis formações e ações que incluam componentes da ST para promoção de situações de trabalho em que se exerçam competências no plano individual e coletivo, em um trabalho emancipador e criativo.

Pela sua posição-chave no relacionamento com a população, evidencia-se mais do que nunca a necessidade do fortalecimento de estratégias nas instituições de proteção e defesa civil para o desenvolvimento e proteção desses profissionais e para a redução do risco de desastres no País.

\section{Colaboradores}

Rezende EA (0000-0002-2625-7045)*, Portella S (0000-0002-1514-7449)* e Oliveira SS (00000002-1477-749X)* contribuíram igualmente na elaboração do manuscrito.

\section{Referências}

1. Quarantelli EL. Uma agenda de pesquisa do século 21 em ciências sociais para os desastres: questões teóricas, metodológicas e empíricas, e suas implementações no campo profissional. Soc. Questão. 2015; 33(18):25-56.

2. Acosta VG. La construcción social de riesgos y El huracán Paulina. Cidade do México: CIESAS; 2005.

3. Valencio NF. Elementos constitutivos de um desas- tre catastrófico: os problemas científicos por detrás dos contextos críticos. Cienc. Cult. 2016; 68(3):41-45.

4. Anazawa TM, Bonatti TF, Carmo RL. O risco construído: reflexões sobre o desastre ocorrido em Mariana, estado de Minas Gerais, em 2015, a partir da perspectiva da relação entre população e ambiente. In: Anais do XX Encontro Nacional de Estudos Populacionais (ANBEP); 2016 Out 17-22; Paraná: Foz do Iguaçu, 2016. p. 1-20. [acesso em 2018 nov 24]. Dispo-
${ }^{*}$ Orcid (Open Researcher and Contributor ID). 
nível em: http://www.abep.org.br/xxencontro/files/ paper/827-763.pdf.

5. Lavell A. Ciencias Sociales y Desastres Naturales en America Latina: Un Encuentro Inconcluso. In: Maskrey A, organizador. Los Desastres no son Naturales. Cidade do Panamá: LaRED; 1993. p. 135-154.

6. Portella S. O desastre e a percepção da percepção social do risco: Mariana, pororoca de lama! ClimaCom [internet]. 2017 [acesso em 2019 mar 19]; 4(9):1-21. Disponível em: http://climacom.mudancasclimaticas.net.br/?p=7426.

7. Cacemiro W, Abeu IS. Tragédia de Mariana (MG): estudo do caso à luz do direito ambiental. Derecho y Cambio Soc [internet]. 2017. [acesso em 2018 jan 7]; 14(50):1-15. Disponível em: http://www.derechoycambiosocial.com/revista050/INDICE_POR.htm.

8. Zhouri A, Valencio N, Oliveira R, et al. O desastre da Samarco e a política das afetações: classificações e ações que produzem o sofrimento social. Cienc. Cult. 2016; 68(3):36-40.

9. Freitas CM, Barcellos C, Asmus CIRF, et al. Da Samarco em Mariana à Vale em Brumadinho: desastres em barragens de mineração e Saúde Coletiva. Cad. Saúde Pública. 2019; 35(5):e00052519.

10. Rocha V. O papel do Agente Comunitário de Saúde na prevenção de desastres por deslizamento em comunidades da cidade do Rio de Janeiro - RJ, Brasil. [tese]. Rio de Janeiro: Escola Nacional de Saúde Pública Sérgio Arouca, Fundação Oswaldo Cruz; 2015. $215 \mathrm{p}$.

11. Minayo-Gomez C. Campo da saúde do trabalhador: trajetória, configuração e transformações. In: Minayo GC, Machado JMH, Pena PGL, organizadores. Saúde do trabalhador na sociedade brasileira contemporânea. Rio de Janeiro: Fiocruz; 2011.

12. Oliveira S. Experiência e produção de saberes, possibilidades de superação das vulnerabilidades: reflexões acerca do desastre da região serrana do Rio de
Janeiro. In: Siqueira A, Valencio N, Siena M, et al., organizadores. Riscos de desastres relacionados à água: aplicabilidade de bases conceituais das Ciências Humanas e Sociais para a análise de casos concretos. São Carlos: RiMa; 2015. p. 291-309.

13. Oliveira S, Portella S. Dimensão singular da atividade dos trabalhadores da saúde: revisitando o desastre da Região Serrana. Tempus, actas de saúde colet. 2019; 13(2):77-90.

14. Brasil. Lei ${ }^{0} 12.608$, de 10 de abril de 2012. Política Nacional de Proteção e Defesa Civil - PNPDEC. Brasília, DF: Diário Oficial da União. 11 Abr 2012.

15. Schwartz Y. Reflexão em torno de um exemplo de trabalho operário. In: Schwartz Y, Durrive L, organizadores. Trabalho \& Ergologia: conversas sobre a atividade humana. 2. ed. Niterói: EdUFF, 2010. p. 3746.

16. Schwartz Y. Do «desvio teórico» à «atividade» como potência de convocação dos saberes. Serv. Soc. Saúde. 2017; 6(6):1-44.

17. Venner B, Schwartz Y. Debates de normas, "mundo de valores" e engajamento transformador. In: Schwartz Y, Durrive L, organizadores. Trabalho e ergologia II: diálogos sobre a atividade humana. Belo Horizonte: Fabrefactum; 2015. p. 55-150.

18. Weber F. A Entrevista, a pesquisa e o íntimo, ou: por que censurar seu diário de campo? Horiz. Antropológicos. 2009; 15(32):157-170.

19. Minayo-Gomez C. Campo da saúde do trabalhador: trajetória, configuração e transformações. In: Minayo Gomez C, Machado JMH, Pena PGL, organizadores. Saúde do trabalhador na sociedade brasileira contemporânea. Rio de Janeiro: Fiocruz; 2011.

20. Alves EGR. Da Psicologia dos desastres à psicologia da gestão integral de riscos e desastres. In: Fukumitsu KO, organizador. Vida, morte e luto: atualidades brasileiras. São Paulo: Summus Editorial; 2018. 
21. Valencio N. Para além do "dia do desastre": o caso brasileiro. Curitiba: Appris; 2012.

22. Oliveira S. Relação saúde-trabalho em situações de desastre. In: Freitas CM, coordenador. Gestão local de desastres naturais para a atenção básica [internet]. São Paulo: Unasus/Unifesp; 2016. p. 98-113. [acesso em 2018 fev 23]. Disponível em: http://moodle.unasus.unifesp.br.

23. Junqueira LA. Intersetorialidade, transetorialidade e redes sociais na saúde. Rev. Adm. Pública. 2000; 34(6):35-45.
24. Siena M, Jesus MR, Santos MA. Os desafios da atuação dos agentes de defesa civil em desastres: uma reflexão a partir das experiências do município de Teresópolis (RJ) e Angra dos Reis (RJ). In: Carmo $\mathrm{R}$, Valencio N, organizadores. Segurança humana no contexto dos desastres. São Carlos: RiMa; 2014. p. 93107.

25. Paladino E, Thomé JT. Psicologia em tempos de tragédia. Rev Mente Céreb. 2011; (221):1-3.

Recebido em 28/09/2019

Aprovado em 04/02/2020

Conflito de interesses: inexistente

Suporte financeiro: não houve 